\title{
SME APPROACH TO ROAD TRANSPORTATION RISK MANAGEMENT: EVIDENCE FROM NIGERIA
}

\author{
IBRAHIM LABARAN ALI ${ }^{1}$, ABIGAIL HIRD $^{1}$, MUHAMMAD TANKO $^{2} \&$ ROBERT IAN WHITFIELD ${ }^{1}$ \\ ${ }^{1}$ Department of Design, Manufacture and Engineering Management University of Strathclyde, UK \\ ${ }^{2}$ Department of Accounting, Kaduna State University, Nigeria
}

\begin{abstract}
The main objective of this study is to investigate how SMEs manage freight transport risk. This study builds on the argument from the contingent resources-based view that, for sustainable competitive advantage, SMEs need to develop capabilities to manage road freight transport risk. These capabilities, consistent with the contingent resource-based view, are approaches in managing road freight transport risk which needs to be lots of unique skills, knowledge and other resources that are commensurate to both the size and the supply chain environment of the SME. To achieve the objective of this study, it is deemed necessary to carry out this research through the lens of SMEs. In doing so, this study adopts a qualitative approach to gain a deeper understanding of SMEs' approach to managing road freight transport risk. Data were collected through interviews from four case companies that were selected using a convenient and purposive sampling strategy. Findings indicated that the sampled SMEs have developed capabilities for managing road transport-related risk. While some of the risk management strategies such as internal control, driver's orientation and partnering with police are common among sampled SMEs, collaboration with partners, specifically with those along transport route, is unique to only one of the SMEs. This study contributes to both the literature and practice of supply chain risk management as it relates to road transportation risk management by being among the few studies that have investigated freight transport risk from an SME perspective.

Keywords: road transportation, risk management, SME, contingent resource-based view, supply chain and logistics.
\end{abstract}

\section{INTRODUCTION}

Cargo theft, armed robbery, bridge collapse, road accidents are some of the risk both that SMEs and large firms face as they transport their goods on most Nigerian roads. Though there are no accurate data about the amount of transport-related losses in Nigeria, but previously in the European Union, for instance, annual cargo related theft - which is one aspect of transport-related risk - was estimated at EUR 8.2 billion [1]. As a result, managing transport related risk is receiving continued attention from researcher, security agencies, local businesses, and even multinational company who operate in developing countries [1], [2].

SMEs are agreed to form a significant portion of the manufacturing sector of most developing economies with presences presence both in urban and rural areas. Like large firms, SMEs use the same transport network facility where they faced similar risks. SMEs in Nigeria are defined as any enterprise that employs between 10 to 199 persons, with assets not exceeding 500 million Naira (equivalent to 1.5 million Dollars). Past studies that investigated risk management in large firms, acknowledged the resources available to them [large firms] in managing road transport risks. SMEs, on the other hand, are small with little resources. Though SMEs have been renowned for innovation and producing customised products in niche markets [3], there is limited knowledge to how they manage their transport related risk.

The main focus of this paper is to investigate how SMEs manage road transporting risk that are likely to occur when they move their raw materials inbound and finished product 
outbound. Although this study was carried out on SMEs in Nigeria, it still reveals several and unique risk management strategies adopted by SMEs which can be beneficial not only to large and multinationals that have branches in Nigeria, but also SMEs and other firms that are facing similar challenges in other countries. This is because based on their size, SMEs are forced to implement effective risk management strategies that will give them both competitive advantages and save them cost [3].

Past studies have investigated cargo theft risk and security [1], incidence of theft along existing home delivery channels [2], success of collision avoidance in the area of passenger transport [4]. Others that focused on road transportation risk management concentrated on express logistics providers [5] and Hazardous materials transportation [6]. On the other hand, most of the SME studies that looked in to risk management didn't not examine road transport risk management [3], [7]-[11]. Underlining the gap in the literature and potentials to gain valuable insight, this study aims to investigate how SMEs manage road transportation risk in their inbound and outbound transport operations.

The remainder of this paper is organised as follows. Section 2 is theoretical background; Section 3 is the methodology; Section 4 is findings and Section 5 conclusion and implications.

\section{THEORETICAL BACKGROUND}

\subsection{Resource-based view}

The resource-based view (RBV) is a renowned theory that has been used in many strategic management researches [12]. RBV centres on the argument that a firm's sustainable competitive advantage arises from its resources that are rare, valuable, hard or impossible to imitate or duplicate, and hard to substitute [13], [14]. Therefore, resources and/or capabilities play a vital role in a firm's development and survival [23]. While tangible resources are common in all businesses, intangible resources such as knowledge, goodwill, inter-personal relationships are also crucial in enhance firms' competitive advantage [15], [16]. According to Hitt [17], intangible resources are more likely to contribute to a firm's competitive advantage because their value cannot be easily substituted and they are more difficult to imitate [12], [14]. In essence, the ability for an organisation to utilize its resources, to perform sets of task to achieve a particular objectives, is a capability that enhances the organisations competitive advantage [18].

\subsection{Contingent RBV}

Despite the prevalence of the RBV within the extant literature, it has been argued that the theory suffers from "context insensitivity" [19]. This suggests that it is unable to identify the conditions in which resources or capabilities may be most valuable [19]. A contingent RBV has been proffered by scholars as it helps to address the somewhat "static nature of the RBV" [20]. Contingencies have been identified as important in the realization of competitive advantage created by resources and capabilities, especially in relation to selection and deployment [14]. Contingency factors such as national context and culture, strategic context, firm size and other organizational variables have been considered within the operations and supply chain management literature [21]. 


\subsection{Contingent RBV and SME Freight Transport risks Management - Nigerian Context}

Given the type of environment which business operates in Nigeria - poor infrastructure and security challenges, SMEs are forced to adapt their supply chains to the environment for competitive advantages by utilizing both tangible and also intangible resources to create capabilities that will enable achieve their goals [22]. Hence, firms have to create dynamic capabilities that will enable them respond to environmental threats [14]. Those firms have to develop idiosyncratic risk management capabilities that will enhance the competitive position of their supply chain as they face various freight transportation risks. According to Barney [23], such capabilities and knowledge [risk management capabilities and knowledge] that are crucial in improving firms' efficiency and effectiveness are valuable resource. Further, when a firms is implementing a unique value-creating strategy that has hitherto, not have been implement by current and potential competitors, the firms is said to have competitive advantage [23]. Hence, this study uses the contingent resource-based view as a theoretical lens to understanding how SMEs create capabilities that are applicable to their environment and context, in managing road transport risk.

\section{METHODOLOGY}

In order to investigate how small and medium-sized enterprises (SMEs) in Nigeria are developing capabilities to manage road transportation risks; a qualitative research strategy was adopted. The research consists of four short explorative case studies carried out with SMEs in Nigeria. The SMEs studied all have business activities that involved use of road transport which they depend on, for inbound and outbound transport of raw materials and finished goods.

All SMEs studied have reported several incidence of transport-related disruption which necessitated the development and implementation of road transportation risk management strategy. The study used the Small and Medium Enterprise Development Agency of Nigeria (SMEDAN) categorization in determining the category of the sampled SMEs used in the studied. Semi-structured interview technique was used to collect information. The interview was conducted in January 2018. In selecting SMEs for the study, a convenient and purposive sampling was utilized, based on the fact that only SMEs that have experienced transport related disruption will provide an in-depth explanation of the strategy they used in managing transport related risk [24]. Interviewees were managers responsible for transportation or logistics in case SMEs. Prior to interview, all participants were informed that their participation was voluntary and they are free to withdraw at any time. Participants were then requested to read and sign a consent form which described the aim of the study. Interviews were conducted at the business premises of case SMEs. All interviews were tape recorded. Both the participants and their firms were assured of anonymity and confidentiality. As a result, rather than use case company names, pseudo names of SME 1, SME 2, SME 3 and SME 4 were used.

\section{FINDINGS}

As shown in Table 1, all sampled SMEs have had experiences of several road transportrelated disruptions which necessitated the development and use of risk management strategy. For instance, in the year 2017, SME 2 documented 8 major road incidences which caused disruption to transportation of their finished product. Like SME 4, SME 2 is in the business of yoghurt which has short shelf life. As a result, constant refrigeration is needed. This in effect means the organisation has serious concern for transport disruption, especially when it relates to their finished product. On the other hand, products of SME 1 
and 3 can last for a longer time and as such, attracts a different type of concern about road transport disruption. Also in Table 1, SME 1 and 2 outsourced all their transportation activity to third-party logistics companies while SME 3 outsourced majority of its own transportation retaining only $30 \%$. On the other hand, SME 3 owned all of its transportation fleet. Interestingly, all SMEs studied [both those that own their fleet of vehicle and those that use third-party logistics] have a risk management strategy for managing transport related risk. The strategies includes internal control measures, relational strategies, takingup insurance policy, driver's orientation, partnering with transport police, collaborating with partners and use of information and communication technology. These strategies are discussed in more detail below.

\subsection{Internal control measures}

The findings of this study reveal how SMEs strengthen their internal control in order to manage road freight risk. According to Christopher and Lee [25], most firms don't have full control over their supply chain operations once it's out of their organisation. As a result, SMEs in the sampled studies have developed and are implementing several internal control measures to manage road freight transport risk. Though internal control is widely used in accounting, from the supply chain risk management point of view, it entails all policies, processes and tasks put in place to facilitate effective operation of the supply chain which enables it to respond to risk. One of the main internal control measures adopted by SMEs is monitoring trucks in-transit. Monitoring of in-transit trucks is carried out through constant communication with drivers. Firstly, where transportation is outsourced, Case 1 adopts several checks and incentives to reduce risks of driver's theft of goods and increase drives delivery time. If you are going to engage a transport company, the union must equally be a party to the agreement ... request for evidences of registration either with insurance and all the necessary authorities (SME 1).

For on-transit vehicles, the sampled SMEs investigated all adopted different communication strategy. Since most of the sampled SMEs lack funds to invest in

Table 1: Case SMEs profile.

\begin{tabular}{|c|c|c|c|c|c|c|}
\hline SME & $\begin{array}{l}\text { Number of } \\
\text { employees }\end{array}$ & $\begin{array}{c}\text { Type of } \\
\text { Business }\end{array}$ & $\begin{array}{l}\text { Age of } \\
\text { SME }\end{array}$ & $\begin{array}{l}\text { Respondent } \\
\text { position }\end{array}$ & $\begin{array}{c}\text { Types of } \\
\text { transport } \\
\text { fleet }\end{array}$ & $\begin{array}{c}\text { Number of } \\
\text { incidence } \\
\text { reported in } \\
2017\end{array}$ \\
\hline $\begin{array}{c}\text { SME } \\
1\end{array}$ & $130-150$ & $\begin{array}{c}\text { Soya Oil } \\
\text { Processing }\end{array}$ & 12 & $\begin{array}{l}\text { Transport } \\
\text { Manager }\end{array}$ & Third party & 6 \\
\hline $\begin{array}{c}\text { SME } \\
2\end{array}$ & $240-280$ & $\begin{array}{l}\text { Food and } \\
\text { Beverage } \\
\text { (Yoghurt) }\end{array}$ & 15 & $\begin{array}{c}\text { Logistic and } \\
\text { Transport } \\
\text { Manger }\end{array}$ & $\begin{array}{c}\text { Own } 30 \% \text {, } \\
\text { Third party } \\
70 \% \\
\end{array}$ & 8 \\
\hline $\begin{array}{c}\text { SME } \\
3\end{array}$ & $50-60$ & $\begin{array}{c}\text { Petroleum } \\
\text { product } \\
\text { transportation } \\
\text { and sales }\end{array}$ & 25 & $\begin{array}{c}\text { Operations } \\
\text { manager }\end{array}$ & Own & 5 \\
\hline $\begin{array}{c}\text { SME } \\
4\end{array}$ & $15-25$ & $\begin{array}{l}\text { Food and } \\
\text { Beverage } \\
\text { (Yoghurt) }\end{array}$ & 3 & $\begin{array}{c}\text { General } \\
\text { Manager }\end{array}$ & Third party & 3 \\
\hline
\end{tabular}

Source: Case SME company data. 
sophisticated communication equipment, constant communications between drivers and managers are maintained in order to update firms on the status of the truck. As a result, one of the sampled SME (SME 1) created a logistic department which have among its duties, is monitoring in-transit truck. On the other hand, Case 4 saddles the responsibility of monitoring in-transit truck to be carried out by the operations manager. "We do make sure that we interact (communicate) with our drivers so as to know their location, know what is going on with them" (SME 2).

Another internal control measures taken to manage road freight transport risk is decentralization of communication. To this end, the SMEs adopt various pattern of communication for in-transit vehicle. For instance, when more than one vehicle are on the route, case 4 emphasize on in-transit vehicles to communicate to head office, which then communicates to the other vehicles. So that is why it is very important [that] when you release a vehicle you have to be calling [communicating with your drivers], you have to be calling. Maybe if they are going to the same route, maybe they are three in number, the first one that goes you have the contact, and the last one, so if something is going on the first one that reach you will have information, immediately you get the information you disseminate it to the others so that they will not fall victim (SME 2). On the other hand, SME 3 prefers on-transit vehicles to communicate with the closest manager on the route, who then communicates to head office. Drivers usually communicate with the managers that are close-by (SME 3).

\subsection{Driver's orientation}

Road freight risks are more likely to be managed when drivers have the right training and orientation of actions to take during crisis. This is because the cultural theory of risk explains that during crisis, an individual is likely to resort to their experiences in order to manage the situation [26]. As a result, sampled SMEs developed guidelines of actions for drivers to take during crisis. One of the strategies is "disguising vehicles", especially when the threat on the route includes kidnapping drivers for ransom. For such route, especially where organisation owned vehicles are used, the vehicles are usually not branded. Further, cash conveyed in the vehicle are hidden while identity of the salesperson in the vehicle is hidden (SME 2).

On the other hand, where the threats are related to armed robbery, drivers are "encouraged to park-and-wait" in a safe location. "So if there is any information as relate to robbery on the road... they just have to park in town for safety of their lives and the goods" SME 2). This strategy is frequently used by all the sampled SMEs. Unlike big firms that can reroute or adopt a multi-modal transportation during crisis, the sampled SMEs are constrained by resources and as such (SME 4).

\subsection{Partnering with police}

Partnering with police is a common practice during crisis and disaster [Dillon, 2014]. Firms that are mindful for the need for safer and secure supply chain are more proactive in establishing relationships with external parties that enhance security of their supply chain [27]. Consequently, SMEs studied are found to be partnering with highway police and antirobbery squad; as a risk management strategy. For instance, Case Two makes the following submission. "Police give us information on the situation of where our trucks are going". In this instance, the partnering relates to receiving information about the situation on the road. This is possible as highway patrols are carried out by the police in roads that are prone to 
armed robbery and other crimes. Further, firms also report crime incidence to police about "hot areas,"i.e. where armed robbery usually take place. As a result, police checkpoints are established in such areas. When they [the police] heard about the robbery, they now station security personnel there (SME 2).

\subsection{Collaborating with partners}

Since transportation falls within the sphere of supply chain activities, factoring it in the broad strategic orientation of most firms/SME supply chain management philosophy which is to a collaborative efforts towards aligning different supply chain stakeholders into a unified whole [28]. In this regards freight transportation risk management is viewed as a collaborative effort by all stakeholders to achieve surplus. Among the firms sampled, SME 2 is unique in adopting a collaborative strategy in managing freight transport risk. In most of the routes, we have our customers that are residing or living very close to that area they will tell you to stay away from that area until it is safe (SME 2). In this instance, customers are relied upon as a means of receive risk information about the condition of the road. If there is any problem, they will let us know, even before we load - that see there is this issue, instead of coming to our place, you should just move to another local government area where there is no challenges (SME 2).

Other strategy adopted is; empowering distributors to provide immediate assistance to vehicles on transit. This was adopted by SME 2 due to the nature of their product. when you have a distributor there [where an event occurs], anything that happens you call your distributor, from there [then] you move to the area where the incident happened, then you relate [get] the information then you see if the situation warrants the driver to be taken to the hospital or something like that, you have to take him to the hospital, and if they are to evacuate or there are some goods are still normal, you can use another vehicle to convey it down to his place (SME 2). This strategy helps the firm especially when it will take a long time for recovery vehicle or staff member to get to the crisis spot and when there is the need to save or secure the goods that are still in good condition.

\subsection{Discussion}

As indicated in the previous sections, there are several ways of managing fright transportation risk based on the risk environment and resources available to the firm. In essence, our results shows SMEs develop capabilities of managing freight transport risk using both internal and external resources. From the internal dimension, SMEs knowledge of the road transportation risk associated with bringing in their raw materials and transporting finished goods; have necessitated the development of internal control mechanisms that will address the various risks. As a result, consistent with the RBV, firms deploy both tangible and intangible resources to manage risks and also to gain competitive advantage [29]. The internal control in this regard relates to the procedures and actions to be taken to manage road freight risk. The control measures starts from pre-engagement with transporters, departure of vehicles, when vehicle are on-transit till point of delivery. Sampled SMEs indicated that the internal control strategies are crucial in reducing their freight transport-related risks.

For specific security-related events such as robbery, kidnapping or communal clashes along travel route, driver's orientation in managing such incidence is important. Since these events are frequent events along the travel route, drivers have been trained and directed to follow certain guidelines in managing such risks. This shows that SMEs are also concerned 
about their driver's safety and thus, drivers are provided with the right orientation of how to manage transport related risk that is likely to occur along travel route. These orientations are similar to driver's orientation in disaster relief environment [30].

Another dimension of road transport risk management by SMEs is partnering with police to gain information about safety of the route or for police deployment in trouble spots appears to be a risk management strategy adopted by SMEs. This is less expensive as compared to employing an arm guard on-board every vehicle on every journey.

Collaboratively, one of the sampled SME has developed unique capabilities of managing freight transport related risk through collaboration with distributors and consumers. Whiles firms encourage risk information sharing from consumers and other partners; they also collaborate with distributors to serve as "first responders" to on-transit vehicle that are in danger. This approach is consistent with the collaborative approach in managing supply chain risk [31]. Hence, apart from the financial implication of this approach - where losses are reduced, the approach also strengthen the relationships between firms which have several advantages [32].

\section{CONCLUSION AND RECOMMENDATIONS}

While existing research mostly focussed on road transport risk management in large companies, the focus of this study in on finding out how SMEs develop capabilities in managing road transport risk that relate to inbound and outbound transport operations. The study interviewed managers responsible for road transportation in four SMEs in Nigeria. Finding indicated that SMEs studied have developed capabilities for managing road transport-related risk. While some of the risk management strategies such as internal control, driver's orientation and partnering with police are common among sampled SMEs, collaboration with partners, specifically with those along transport route, is unique to only one of the SME in the study. This is consistent with the argument in support of contingent RBV. Though some aspect of the risk management strategy used by SMEs in this study might be considered by other large firms or other SMEs, it is foremost to note that the major limitation of this study is that its findings are limited to only four case studies. Nonetheless, a qualitative study of this kind is aimed at bringing rich description of a phenomenon from the point of view of the cases. An insight for future research will be to conduct an exploratory sequential research where the findings of this study are tested in a larger population using quantitative techniques.

Nonetheless, the findings of this study will be useful to developing countries where the focus is on empowering SMEs in order to solve most of their social and economic problems. As a result, the findings of this study will be beneficial to policymakers. Also, SMEs, large firms and multi-national companies may gain valuable insights from the finding of this study, specifically in assessing their existing road transportation risk management strategy. Finally, the finding of this study extends the literature in transport risk management and SME studies.

\section{REFERENCES}

[1] Ekwall, D. \& Lantz, B., Cargo theft risk and security: product and location. Proceedings of Nofoma, pp. 1-17, 2017.

[2] Mckinnon, A. \& Tallam, D., New crime threats from e-tailing: Theft in the home delivery channel report prepared for the products and crime task force of the UK Government Foresight Programme, 2002. Online. www.alanmckinnon.co.uk/ uploaded/PDFs/Papers/Theft-in-the-Home-Delivery-Channel-(Foresight-Programme-McKinnon-and-Tallam-April_2002).pdf. 
[3] Sunjka, B.P. \& Emwanu, B., Risk Management in Manufacturing SMEs in South Africa. International Association for Management of Technology IAMOT 2015 Conference Proceedings RISK. pp. 1469-1486, 2015.

[4] Langard, B., Morel, G. \& Chauvin, C., Collision risk management in passenger transportation: A study of the conditions for success in a safe shipping company. Psychologie Francaise, 60(2), pp. 111-127, 2015. DOI: 10.1016/j.psfr.2014.11.001.

[5] Yang, Q., Chin, K.S. \& Li, Y.L., A quality function deployment-based framework for the risk management of hazardous material transportation process. Journal of Loss Prevention in the Process Industries. 52, pp. 81-92, 2018.

DOI: 10.1016/j.jlp.2018.02.001.

[6] Wang, H., Tan, J., Guo, S. \& Wang, S., High-value transportation disruption risk management: Shipment insurance with declared value. Transport Research Part E: Logistics and Transportation Review, 109, pp. 293-310, 2018.

DOI: 10.1016/j.tre.2017.11.013.

[7] Crick, F., Eskander, SMSU., Fankhauser, S. \& Diop, M., How do African SMEs respond to climate risks? Evidence from Kenya and Senegal. World Development, 108, pp. 157-68, 2018. DOI: 10.1016/j.worlddev.2018.03.015.

[8] Sifumba, C.M., Mothibi, KB., Ezeonwuka, A. \& Town, C., The risk management practices in the manufacturing SMEs in Cape Town. Problems and Perspectives in Management, 15(2), pp. 386-403, 2017. DOI: 10.21511/ppm.15(2-2).2017.08.

[9] Ali, I., Nagalingam, S. \& Gurd, B., Building resilience in SMEs of perishable product supply chains: enablers, barriers and risks. Production Planning \& Control, 28(15), pp. 1236-50, 2017. DOI: 10.1080/09537287.2017.1362487.

[10] Iopev, L. \& Kwanum, I.M., An assessment of risk management of small and medium scale enterprises in Nigeria. Research Journal of Finance and Accounting, 3(5), 2222-2847, 2012.

[11] Thun, J.-H., Drüke, M. \& Hoenig, D., Managing uncertainty-an empirical analysis of supply chain risk management in small and medium-sized enterprises. International Journal of Production Research, 49(18), pp. 5511-5525, 2011. DOI: 10.1080/00207543.2011.563901.

[12] Hitt, M.A., Carnes, C.M. \& Xu, K., A current view of resource-based theory in operations management: A response to Bromiley and Rau. Journal of Operations Management, 41, pp. 107-109, 2016. DOI: 10.1016/j.jom.2015.11.004.

[13] Bromiley, P. \& Rau, D., Operations management and the resource-based view: Another view. Journal of Operations Management, 41, pp. 95-106, 2016.

DOI: 10.1016/j.jom.2015.11.003.

[14] Sirmon, D.G., Hitt, M.A., Duane, R., Brett, I. \& Gilbert, A., Resource orchestration to create competitive advantage: breadth, depth, and life cycle effects. Journal of Management, 37(5), pp. 1390-1412, 2011.

[15] Sirmon, D.G., Hitt, M.A. \& Duane Ireland, R., Managing firm resources in dynamic environments to create value: looking inside the black box. The Academy of Management Review 32(1), pp. 273-292, 2007.

[16] Pal, R., Torstensson, H. \& Mattila, H., Antecedents of organizational resilience in economic crises - an empirical study of Swedish textile and clothing SMEs. International Journal of Production Economics, 147, pp. 410-28, 2014.

DOI: 10.1016/j.ijpe.2013.02.031.

[17] Hitt, M.A., Bierman, L., Uhlenbruck, K., Shimizu, K., Hitt, M.A. \& Bierman, L., The importance of resources in the internationalization of professional service firms: The 
good, the bad, and the ugly. Academy of Management Journal, 49(6), pp. 1137-1157, 2006. DOI: 10.5465/amj.2006.23478217.

[18] Helfat, C.E. \& Peteraf, M.A., The dynamic resource-based view: Capability lifecycles. Strategic Management Journal, 24(10), pp. 997-1010, 2003.

DOI: $10.1002 / \mathrm{smj} .332$.

[19] Pateman, H., Cahoon, S. \& Chen, S.-L., The role and value of collaboration in the logistics industry: An empirical study in Australia. The Asian Journal of Shipping and Logistics, 32(1), pp. 33-40, 2016. DOI: 10.1016/j.ajsl.2016.03.004.

[20] Brandon-Jones, E., Squire, B., Autry, C.W. \& Petersen, K.J., A contingent resourcebased perspective of supply chain resilience. Journal of Supply Chain Management, 50(3), pp. 55-73, 2014. DOI: $10.1111 /$ jscm. 12050.

[21] Sousa, R. \& Voss, C.A., Contingency research in operations management practices. Journal of Operations Management, 26(6), pp. 697-713, 2008.

DOI: 10.1016/j.jom.2008.06.001.

[22] Ambituuni, A., Amezaga, J.M. \& Werner, D., Risk management framework for safe transportation of petroleum products in Nigeria: Learning from past accidents and good practices. Risk Management, 17(4), pp. 329-351, 2015.

DOI: $10.1057 / \mathrm{rm} .2015 .18$.

[23] Barney, J., Firm, resource and sustained competitive advantage. Journal of Management. 17(1), pp. 99-120, 1991.

[24] Creswell, J.W., Qualitative Inquiry and Research Design: Choosing Among Five Approaches, SAGE Publications, 2018.

[25] Christopher, M. \& Lee, H., Mitigating supply chain risk through improved confidence. International Journal of Physical Distribution \& Logistics Management, 34(5), pp. 388-396, 2004. DOI: 10.1108/09600030410545436.

[26] Xu, S. \& Sifan Xu, C., When individual cultural orientation and mediated portrayal of risk intersect: Effects of individualism-collectivism and media framing on risk perception and attribution of responsibility. Journal of Contingencies and Crisis Management, pp. 1-11, 2008.

[27] Speier, C., Whipple, J.M., Closs, D.J., Voss, M.D. \& Mcconnell, J.H., Global supply chain design considerations: Mitigating product safety and security risks. Journal of Operations Management. 29(7-8), pp. 721-736, 2011.

DOI: $10.1016 /$ j.jom.2011.06.003.

[28] Mentzer, J.T., Min, S. \& Zacharia, Z.G., The nature of interfirm partnering in supply chain management. Journal of Retailing, 76(4), pp. 549-568, 2000.

DOI: 10.1016/s0022-4359(00)00040-3.

[29] Grant, R.M., The resource-based theory of competitive advantage: Implications for strategy formulation. California Management Review, 33(3), pp. 114-135, 1991. DOI: $10.2307 / 41166664$.

[30] De la Torre, L.E., Dolinskaya, I.S. \& Smilowitz, K.R., Disaster relief routing: Integrating research and practice. Socio-Economic Planning Sciences, 46(1), pp. 8897, 2012. DOI 10.1016/j.seps.2011.06.001.

[31] Chen, J., Sohal. A.S. \& Prajogo, D.I., Supply chain operational risk mitigation: A collaborative approach. International Journal of Production Research, 51(7), pp. 2186-2199, 2013. DOI: 10.1080/00207543.2012.727490.

[32] Li, G., Fan, H., Lee, PKC. \& Cheng, T.C.E., Joint supply chain risk management: An agency and collaboration perspective. International Journal of Production Economics, 164, pp. 83-94, 2015. DOI: 10.1016/j.ijpe.2015.02.021. 